\title{
Comparison of the Effects of Dry Needling and Low-Level Laser on the Latent Trigger Points of Upper Trapezius
}

\author{
Afsaneh Seifolahi ${ }^{1}$, Tahere Rezaeian ${ }^{2}$, Zahra Mosallanezhad ${ }^{2}$ and Sedigheh Sadat Naimi ${ }^{3,}{ }^{*}$ \\ ${ }^{1}$ PhD Candidate, Department of Physical Therapy, Faculty of Rehabilitation Sciences, University of Social Welfare and Rehabilitation Sciences, Tehran, Iran \\ 2 PhD in Physical Therapy, Department of Physical Therapy, Faculty of Rehabilitation Sciences, University of Social Welfare and Rehabilitation Sciences, Tehran, Iran \\ ${ }^{3} \mathrm{PhD}$ in Physiotherapy, Associate Professor, Physiotherapy Research Center, Department of Physiotherapy, Faculty of Rehabilitation, Shahid Beheshti University \\ of Medical Sciences, Tehran, Iran
}

* Corresponding author: Sedigheh Sadat Naimi, Physiotherapy Research Center, Department of Physiotherapy, Faculty of Rehabilitation,

Shahid Beheshti University of Medical Sciences, Tehran, Iran. Email: naimi.se@gmail.com

Received 2020 November 18; Revised 2020 December 13; Accepted 2021 January 07.

\begin{abstract}
Background: Myofascial pain syndrome (MPS) is one of the most frequent causes of chronic musculoskeletal pain which is characterized by myofascial trigger points (MTrPs). Hence, it is of crucial importance to identify practical approaches for the treatment of these points. Upper trapezius muscle (UT) is highly susceptible to the development of MTrPs that are commonly resulted from overuse and micro-trauma.

Objectives: The present study aimed to compare the effects of dry needling (DN) and low-level laser therapy (LLLT) regarding the reduction of pain and muscle thickness and improvement of the range of motion (ROM) and pressure pain threshold (PPT) in patients with latent MTrPs (LTrPs) in their UT muscles.

Methods: In total, 60 patients with LTrPs in UT muscle participated in this randomized clinical trial. The subjects were randomly divided into two treatment groups of DN and LLLT. The PPT was evaluated by visual analog scale (VAS) and algometer while ROM and muscle thickness were assessed using goniometer and ultrasonography, respectively. It should be noted that the variables were evaluated before the first and after the sixth sessions. Finally, the collected data were analyzed using independent and paired t-tests.

Results: Based on the results, the VAS and muscle thickness significantly reduced, while the PPT and cervical ROM increased in both groups after treatment $(\mathrm{P}<0.001)$. The independent $\mathrm{t}$-test revealed a statistically significant improvement in the DN group in terms of PPT (9.9-14.17, $\mathrm{P}=0.009)$ and ROM (37.33-42.67, $\mathrm{p}=0.005)$, compared to the LLLT group. Nevertheless, no significant difference was found between the two groups regarding VAS and muscle thickness variables $(\mathrm{P}>0.05)$.

Conclusion: The DN and LLLT effectively improved symptoms in the UT muscles of patients with LTrPs. However, the DN was more effective in the improvement of ROM and PPT variables.
\end{abstract}

Keywords: Dry needling, Low-level laser, Trigger point, Upper trapezius

\section{Background}

Myofascial pain syndrome (MPS) is a painful musculoskeletal disorder characterized by myofascial trigger points (MTrPs), which are painful or hyperalgesic spots located within taut bands of skeletal muscle fibers, fascia, ligaments, and tendons $(1,2)$. The MTrPs are categorized as active or latent based on their particular clinical manifestation. Active MTrPs are spontaneously painful and associated with referred symptoms.

However, latent MTrPs (LTrPs), present with muscle shortening or weakness and movement restriction that inflict pain on the application of external stimuli, such as palpation and compression $(1,3)$. Both trigger points can be activated by various stimuli, including posture, overuse, or muscle imbalance (1). In the upper quadrant, postural muscles, mainly the upper trapezius (UT), are mostly affected by MTrPs (4). The prevalence rates of the left and right UT are $23 \%$ and $20 \%$, respectively. No significant relationship has been found between gender and LTrP prevalence in the left or right UT (5).

Various invasive (e.g., acupuncture, dry needling,
MTrP injections with a local anesthetic, saline, and steroid) and non-invasive (e.g., pharmacological treatments, modalities, and manual techniques) treatment methods are currently applied to alleviate the associated pain. Modalities include superficial heat, deep heat (e.g., ultrasound and low-level laser therapy), transcutaneous electrical stimulation, biofeedback, and thermotherapy (6). Manual techniques include proprioceptive neuromuscular facilitation, ischemic compression, stretch exercises with vapor coolant sprays; muscle energy technique (MET), strain counterstrain, and myofascial release (7).

Dry needling (DN) could be a negligibly intrusive strategy that involves inserting an acupuncture-like needle into the MTrP site (6) without medication in order to reduce pain and restore the range of motion (8). Possible mechanisms of dry needling include mechanical, neurophysiologic, and chemical effects $(9,10)$. Regarding the mechanical effect, needling provides a localized stretch to the cytoskeletal structures which causes sarcomeres to return to their relaxation length by reducing the amount of overlap between actin and myosin. The total fiber length change may activate the gate control system and

Copyright (c) 2021, Author(s). This is an open-access article distributed under the terms of the Creative Commons Attribution-NonCommercial 4.0 International License (http://creativecommons.org/licenses/by-nc/4.0/) which permits copy and redistribute the material just in noncommercial usages, provided the original work is properly cited 
cause pain alleviation (11).

Regarding the neurophysiologic effects, A-delta nerve fibers are stimulated for as long as $72 \mathrm{~h}$ after needle insertion which activates the enkephalinergic inhibitory dorsal horn interneurons and causes opioid-mediated pain suppression (11) and recovery of circulation $(10,11)$. Based on the gate control theory of pain, the activation of A-delta nerve fibers, when the needle perforates the skin, inhibits $C$ fibers that carry MTrP pain impulses. Finally, regarding the chemical effect, the increased levels of various chemicals at MTrPs sites, such as bradykinin, calcitonin gene-related peptide, and substance $\mathrm{P}$, are immediately corrected by the evocation of an LTR with an acupuncture needle $(11,12)$.

The most frequently utilized Conceptual model to support the use of DN is the trigger point model originated from the observations of Travell (19011997) $(1,9)$. According to this model, DN is the fastest and most effective intervention for the reduction of pain by targeting MTrPs. The DN relieves all symptoms (i.e., sensory, motor, and autonomic) and interrupts end-plate motor noise by the evocation of the LTR. Furthermore, DN relaxes actin-myosin bonds when accompanied by stretching; therefore, it induces an analgesic effect, normalizes muscle tone, and affects the flow of acetylcholinesterase, bradykinin, calcitonin, and substance P levels $(8,10)$. In this MTrPs treatment model, other interventions should be employed, such as stretch exercises, joint mobilization, neuromuscular reeducation, and muscle empowerment (13).

A laser is a form of photonic therapy with characteristics, such as collimation, convergence, and monochromaticity (14). Low-level laser (light) therapy (LLLT) refers to the application of light with the wavelength of $660-905 \mathrm{~nm}$ which is non-invasive and painless. These wavelengths have no macroscopic thermal effects (sometimes termed cold laser) and are only photochemical $(15,16)$. Moreover, unlike nonsteroidal anti-inflammatory medications which are not effective after discontinuation, the positive effects of these wavelengths are maintained for as long as one-fourth of a year after the termination of the intervention (17).

It can be said that the analgesic effect of LLLT works through a mechanism or a combination of various mechanisms. These mechanisms include the increase of blood perfusion, collagen production stimulation, peripheral nerve stimulation, antiinflammatory response (by the decrease of prostaglandin activity), relaxation of tight bands, and inhibition of transmission at the neuromuscular junction $(2,15,18,19)$. Selective inhibition of nerve conduction has been shown in $\mathrm{A} \delta$ and $\mathrm{C}$ fibers which conveys nociceptive stimulation and laser-induced neural blockade. These inhibitory effects can be mediated by the disruption of fast axonal flow in neurons or the inhibition of neural enzymes $(15,19)$.

Application of LLLT improves the local microcirculation by increasing oxygen supply to hypoxic cells in the MTrP area, interrupting the vicious cycle of the origin of the pain, and removing the waste products (18). The patients with intense or ongoing neck torment and constant trapezius myalgia can benefit from the improvement of microcirculation, reduction of oxidative stress and muscular fatigue (preceding muscle pain), and decrease of electromyographic activity during contractions. Such effects could mediate the clinical finding that LLLT decreases tenderness in trigger points within $15 \mathrm{~min}$ of application (15).

As already mentioned, there are many interventions for the treatment of trigger points, including DN and LLLT; however, there are some controversies regarding their effectiveness. For instance, while the results of certain studies indicate the effectiveness of DN $(6,8,20-23)$ and $\operatorname{LLT}(2,14$, $24-26)$, other studies claim that DN $(27,28)$ and LLLT $(29,30)$ are of no efficacy.

Given the aforementioned mechanisms of DN and LLLT, it was assumed that MTrP pain can be reduced by the analgesic effect of these interventions and the improvement of local circulation. Furthermore, it was considered that the relaxation of actin-myosin bonds can reduce muscle spasm which affects muscle thickness, enhances the range of motion (ROM), and improves the functional condition of the muscle as well $(1,31)$.

The outcome measures in most of the studies that examined the effects of DN or LLT on UT LTrPs included Visual analog scale (VAS), ROM, and pressure pain threshold (PPT) $(22,26)$. However, it seems like that no studies have investigated the changes in muscle thickness. Unlike needle electromyography (EMG), which is invasive (32), real-time ultrasonography is non-invasive and can be reliable for the measurement of the UT thickness (33).

The simultaneous measurement of muscle thickness, pain, PPT, and ROM in LTrPs of UT muscle may be of particular significance in understanding the effects of these two interventions on the conditions of the muscle.

\section{Objectives}

The present study aimed to evaluate and compare the effectiveness of these two methods in the treatment of UT LTrPs to shed some light on the underlying mechanisms and, hopefully, to introduce a better treatment approach.

\section{Methods}

\subsection{Setting}

A single-blinded randomized clinical trial was conducted at the electrophysiology and biomechanics laboratory of Physical Therapy Research Center (PTRC) in Shahid Beheshti University of Medical 
Sciences (SBMU) Tehran, Iran, from August 2015 to February 2016. The PTRC Research Ethics SubCommittee approved this research project. It was a single-blind study since an examiner and a therapist were employed to perform the research separately. The examiner and data analyst were not informed about the treatment method and intervention chosen for the patients.

\subsection{Participants}

The participants were selected from physiotherapy clinics of SBMU. They were informed of the study through notices that were put on the notice boards of the clinics. The subjects were within the age range of 18-50 years and diagnosed with UT LTrPs. Presence of MTrPs of UT in the participants was identified using Travel and Simons' diagnostic criteria (1999) (1) that is as follows:

- Presence of a palpable taut band

- Presence of a tender knot

- Reproduction of pain by compression

- Local twitch response provoked by the snapping palpation of the taut band

- Spontaneous pain recognition

The subjects were requested to sit straight; afterward, the therapist palpated the muscle from its origin attachments to the cervical vertebra to the acromion process in order to diagnose the presence of a nodule. While localizing the nodule, she applied a steady pressure over the hypersensitive tender spot with the algometer at an approximate rate of $1 \mathrm{~kg} /$ $\mathrm{cm} 2 / \mathrm{s}$ until it recorded a $2.5 \mathrm{~kg} / \mathrm{cm}^{2}(25 \mathrm{~N})(34,35)$. If the referred pain (at least three on VAS) evoked by the $\mathrm{MTrP}$ was perceived before $2.5 \mathrm{~kg} / \mathrm{cm}^{2}(25 \mathrm{~N})$, the patient was considered to have Travell and Simons' third criterion (34-36). If the first three essential criteria for the diagnosis of MTrPs were met, MTrP was considered an LTrP of UT marked with a cross using a skin-marker.

Only one LTrP was chosen for the treatment, and if there were more than one LTrP unilaterally or bilaterally, the most symptomatic one was selected; hence, there may have been untreated LTrPs (37). It must be mentioned that the subjects who had no palpable nodules were excluded from the study. The participants were separated into two groups with similar age, gender, and body mass index (BMI). They were also informed about the test procedures and asked to filled the consent form. All the participants had the option to quit the treatment procedures in case of any uneasiness.

The exclusion criteria were 1) pregnancy, 2) needle-phobia, 3) usage of anticoagulants (except for acetylsalicylic acid at dosages up to $325 \mathrm{mg} /$ day), 4) infliction with bleeding disorders and any dermatological diseases (i.e., skin lesion, infection, or inflammatory edema) at the $\operatorname{MTrP}$ sites $(4,38), 5)$ a history of infectious, inflammatory, tumoral, cardiopulmonary, psychiatric, and systemic diseases,
6) Kellgren stage three or four osteoarthritides of the cervical spine or cervical disk herniation causing radiculopathy $(2,4), 7)$ active MTrPs, and 8) inability to understand the instructions or complete the questionnaire (38).

\subsection{Intervention}

The cases were randomly divided into two similar groups (randomization was concealed using the numbered envelope method) with 30 patients with LTrPs in each group. The subjects in the DN group received six therapeutic sessions of DN twice a week with daily stretch exercises for three weeks. Those in the LLLT group received six therapeutic sessions of LLLT twice a week with daily stretch exercises for three weeks. The subject sat straight on a chair to stretch the UT and leaned backward with their hands placed on their thighs. They started to stretch the muscle slowly and gradually with contralateral neck side flexion and ipsilateral neck rotation for $30 \mathrm{sec}$ and relaxed afterward for $30 \mathrm{sec}$. The 30 -sec intervals were repeated three times consecutively and three times during a day (39).

In the DN group, while the patient was in a prone position, the physiotherapist wore surgical gloves, sterilized the area with an alcohol pad, and used pincer palpation to identify the LTrP of UT. An acupuncture needle $(0.3 \times 30 \mathrm{~mm}, 0.25 \mathrm{gr})(40,41)$ was placed over the LTrP. The DN was carried out by the fanning technique in which the needle is repeatedly withdrawn from the LTrP and reinserted to penetrate a new part of the LTrP at a different angle for $10 \mathrm{sec}(42)$. The needle retention time was five min to let it exert its analgesic effects (43).

In the LLLT group, a Ga-As-Al laser probe (one $\mathrm{cm}$ in diameter) with the power output of $100 \mathrm{~mW} / \mathrm{cm} 2$, the frequency of $9.12 \mathrm{~Hz}$ that emitted a laser beam with $830 \mathrm{~nm}$ wavelength was applied directly and perpendicularly into the skin. A total duration of three min and nine-sec irradiation with a dose of $5 \mathrm{~J} / \mathrm{cm}^{2}$ on UT LTrP was considered one irradiation dose.

\subsection{Outcome measure}

The outcome measures included VAS, ROM, PPT, and muscle thickness. All evaluations were performed and recorded at baseline and after the sixth treatment session in the third week.

\subsubsection{Pain intensity}

The VAS was used to measure the current level of pain. The therapist applied a continuous perpendicular pressure at an approximate rate of one $\mathrm{kg} / \mathrm{cm}^{2} / \mathrm{s}$ with the tip of the algometer over the cross, signifying the MTrP location. When the recorded pressure reached $2.5 \mathrm{~kg} / \mathrm{cm}^{2}(25 \mathrm{~N})$, the subjects were asked to rate the pain from 0 (no pain at all) to 10 (the most unbearable pain). If the pain level was low (based on VAS) before the pressure reached 2.5 $\mathrm{kg} / \mathrm{cm}^{2}$, the therapist would start to record the other 
baseline measurements. If it was less than three, the subject was excluded from the study (44). The VAS is a reliable and valid outcome measure and has been used extensively in research about neck pain $(34,35)$.

\subsubsection{Cervical range of motion}

For the purposes of the study, the cervical ROM (CROM) of the participants was measured by a goniometer (45). The subjects were asked to sit upright on the edge of a plinth with knees and hips at 90 degrees and soles on the ground. Fulcrum of the goniometer was placed on the spinous process of the first thoracic spine with the center of the goniometer arm on the occipital protuberance at right angles. Subsequently, the horizontal arm of the device was stabilized manually, and its vertical arm was moved according to the movement of the head of the subject to measure the lateral flexion angle (46). The CROM device demonstrated good-to-excellent inter-rater reliability (0.73-0.89) (47).

\subsubsection{Pressure pain threshold}

Pressure pain threshold refers to the minimal amount of pressure that initiates pain (48). The International Association for the Study of Pain defines PPT as the stimulation of the least sensitivity of patients to pain. This definition of PPT value has been proven to be reliable, reproducible, and valid $(49,50)$. A pressure algometer (Taiwan model 5120) was used in this study which consisted of a round disk with a rubber tip $\left(1 \mathrm{~cm}^{2}\right)$ pressed vertically on the LTrP. The whole procedure was explained to the subjects, and the examiner applied a perpendicular pressure on the identified LTrP which was steadily increased at a rate of one $\mathrm{kg} / \mathrm{cm}^{2} / \mathrm{s}(34,35)$. When the subject felt pain or discomfort, the pressure was withdrawn, and the value was recorded. This procedure was performed three times with 10 -sec intervals, and the mean value was determined as the PPT.

\subsubsection{Muscle thickness}

The change in muscle thickness was measured with an ultrasonic apparatus with a $7.5 \mathrm{MHz}$ linear array transducer (50 mm) (HS 2100, Honda Co. Japan). The ultrasound image was captured using the real-time B mode ultrasound imaging (RUSI). While the subject kept their head and neck in a neutral prone position, a pillow was placed under their abdomen to reduce lumbar lordosis. The case was in a prone position with the upper arms abducted to 90 degrees and the forearms pronated and supported on a plinth in a way that the palms faced the plinth (Figure 1).

The transducer was held horizontally over the UT by the exertion of the minimum pressure required to achieve a clear image. The UT bulk, superior to the attachment of supraspinatus to the spine of the scapula, was the landmark introduced for the measurement of the UT thickness. Muscle thickness

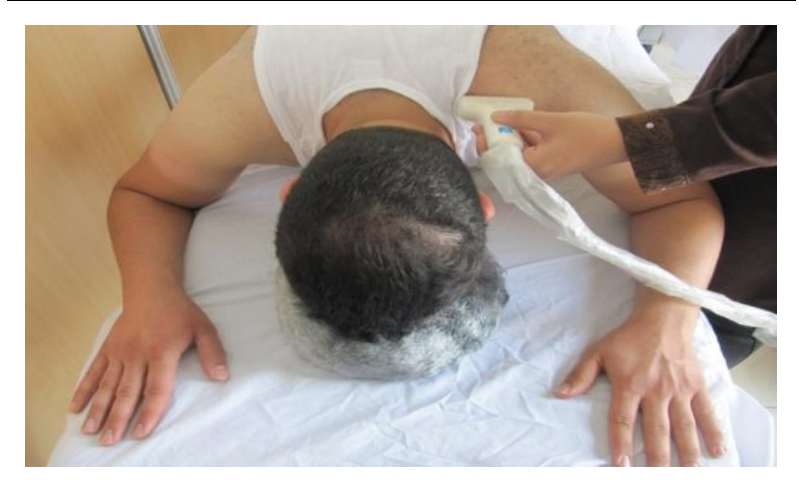

Figure 1. Position of the patient for the measurement of UT thickness

was determined based on the interval among the upper and lower fascial borders of the muscle belly. The evaluation was based on the bright-line edge representing the inner part of superior fascia borders, to the bright-lines edge representing the inner part of the inferior fascial border. Images were frozen on the screen at the end of expiration without informing the patient (Figure 2).

Reliability of ultrasonography measurement for UT thickness was assessed by two physiotherapists on 15 female subjects diagnosed with LTrPs of UT using the above-mentioned procedure. In total, four images of UT muscle were taken by two examiners on the same day with two-h intervals to assess withinday and interexaminer reliability. The intra-class correlation coefficients (ICC), standard errors of measurement (SEM), and the smallest detectable difference (SDD) were computed to test the reliability of the thickness measurements of the UT using RUSI (Table 1). The results are summarized in Table 1 (51)

\subsection{Procedure}

After examination of the inclusion criteria, the subject was asked to perform a neck contralateral lateral flexion in order to allow the therapist to measure the ROM. Afterward, the examiner recorded

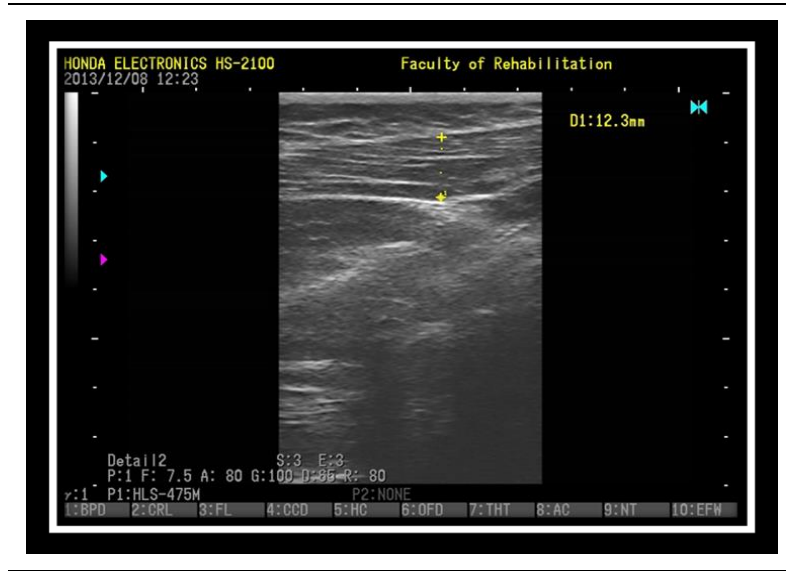

Figure 2. Measurement of upper trapezius thickness superior to the attachment of supraspinatus to the spine of the scapula as indicated by the distance between two pluses 


\begin{tabular}{|c|c|c|c|c|c|}
\hline \multicolumn{2}{|c|}{ Muscle thickness mean value (mm) } & ICC $(95 \% \mathrm{CI})$ & SEM (mm) & SDD (mm) & p-value \\
\hline Examiner 1 & 10.384 & $0.950(0.983-0.857$ & 0.498 & 1.380 & $<0.001$ \\
\hline Examiner 2 & 10.288 & $0.957(0.985-0.878)$ & 0.559 & 1.552 & $<0.001$ \\
\hline Interexaminer & 0.0966 & $0.872(0.949-0.748)$ & 0.891 & 2.472 & $<0.001$ \\
\hline
\end{tabular}

CI: confidence intervals, ICC: intra-class correlation coefficient, mm: millimeters, SEM: standard error of Measurement, SDD: smallest detectable difference

PPT and VAS with a pressure algometer. The ROM and PPT were repeated in the above-mentioned intervals. Subsequently, the examiner measured the UT thickness in the above-mentioned position. In the end, the subject learned the maneuver and the frequency of the daily stretching exercise of UT. In another room, the therapist performed DN or LLLT based on the randomization scheme (sealed opaque envelopes containing the assigned treatment).

\subsection{Statistical analysis}

For the calculation of sample size, type I and II errors were assumed at $\alpha=0.05$ and $\beta=0.2$, respectively (power 80\%). Moreover, the required means and standard deviations were extracted from a study conducted by Ibdulu et al. (2004) (26). Based on the results, 30 subjects were needed in each group (in total 60 subjects).

Descriptive statistics were performed on the demographic characteristics of the samples in the SPSS software (version 23). Moreover, the Kolmogorov-Smirnov and the Levene tests were used to analyze the normality of the distribution of variables and evaluate the equality of variances, respectively. In addition, independent and paired ttests were employed for intergroup and intragroup comparisons, respectively. Furthermore, effect sizes were calculated using intragroup Cohen's d coefficient, and the ICC and SEM were used to assess the intra-tester reliability of the measurement. It must be noted that in all the tests, a p-value of less than 0.05 was considered statistically significant.

\section{Results}

In total, 60 participants were included in the study who were equally divided into the DN and LLLT groups. Mean age of subjects in the DN and LLLT groups were $37.60 \pm 8.55$ and $36.83 \pm 8.83$, respectively. There was no considerable variation in the distribution of gender, age, weight, and BMI (Table 2). The outcomes indicated the typical order of variables in both groups $(\mathrm{P}>0.05)$.

\subsection{Intragroup comparison of the intervention groups}

The VAS, PPT, ROM, and muscle thickness improved significantly in both groups. The mean VAS and muscle thickness decreased after the intervention in the DN and the LLLT groups after the intervention $(\mathrm{P}<0.001)$ (Table2). Furthermore, the mean value of PPT of UT muscle and ROM increased in the DN and the LLLT groups after the treatment $(\mathrm{P}<0.001)$ (Table 3). Intragroup effects sizes for both groups were extensive $(\mathrm{d}>1)$ in all outcomes.

4.2. Intergroup comparison of the outcome measurement Analysis of the data of the two groups revealed

\begin{tabular}{|c|c|c|c|}
\hline Variables & $\begin{array}{c}\text { Dry needling } \\
\text { group } \\
(\mathrm{n}=30)\end{array}$ & $\begin{array}{c}\text { Laser } \\
\text { group } \\
(\mathrm{n}=30)\end{array}$ & P-value ${ }^{1}$ \\
\hline Age (years) & $37.60 \pm 8.55$ & $36.83 \pm 8.83$ & 0.21 \\
\hline Weight (kg) & $62.67 \pm 8.13$ & $61.50 \pm 8.73$ & 0.34 \\
\hline Height (m) & $1.59 \pm 0.65$ & $1.61 \pm 0.65$ & 0.61 \\
\hline BMI $(\mathrm{kg} / \mathrm{m} 2)$ & $24.79 \pm 3.15$ & $23.55 \pm 3.19$ & 0.25 \\
\hline VAS (score) & $7.00 \pm 1.85$ & $7.17 \pm 1.78$ & 0.72 \\
\hline PPT (score) & $9.90 \pm 3.96$ & $9.59 \pm 2.81$ & 0.72 \\
\hline ROM ( Degree) & $37.33 \pm 2.57$ & $37.30 \pm 4.38$ & 0.97 \\
\hline $\begin{array}{l}\text { Muscle thickness } \\
\text { (mm) }\end{array}$ & $12.24 \pm 2.78$ & $11.73 \pm 2.58$ & 0.46 \\
\hline \multicolumn{4}{|c|}{$\begin{array}{l}\text { BMI: body mass index, VAS: visual analog scale, PPT: pressure } \\
\text { pain threshold, ROM: Range Of Motion, p-value }{ }^{1} \text { indicates } \\
\text { significance at } \mathrm{P}<0.05 \text { (intergroup comparison according to the } \\
\text { independent } t \text {-test) }\end{array}$} \\
\hline
\end{tabular}

\begin{tabular}{|c|c|c|c|c|c|c|c|}
\hline \multirow{2}{*}{ Variables } & & \multirow{2}{*}{$\begin{array}{l}\text { Dry needling } \\
\text { group }\end{array}$} & \multirow{2}{*}{$\begin{array}{l}\text { Laser } \\
\text { group }\end{array}$} & \multirow{2}{*}{$\begin{array}{c}\begin{array}{c}\text { P-value }{ }^{1} \\
\text { (dry needling) }\end{array} \\
\text { Pre-post } \\
\text { treatment }\end{array}$} & \multirow{2}{*}{ Cohen's d } & $\begin{array}{c}\text { P value }{ }^{1} \\
\text { (laser therapy) }^{-}\end{array}$ & \multirow{2}{*}{ Cohen's d } \\
\hline & & & & & & $\begin{array}{l}\text { Pre-post } \\
\text { treatment }\end{array}$ & \\
\hline \multirow{2}{*}{ VAS (score) } & Pre-treatment & $7.00 \pm 1.85$ & $7.17 \pm 1.78$ & $t=10.85$ & \multirow{2}{*}{1.14} & $t=9.84$ & \multirow{2}{*}{1.14} \\
\hline & Post-treatment & $4.83 \pm 1.94$ & $5.33 \pm 1.42$ & $<0.001$ & & $<0.001$ & \\
\hline \multirow{2}{*}{ PPT (Kg/cm2) } & Pre-treatment & $9.90 \pm 3.96$ & $9.59 \pm 2.81$ & $t=8.90$ & \multirow{2}{*}{1.15} & $t=10.85$ & \multirow{2}{*}{0.96} \\
\hline & Post-treatment & $14.17 \pm 3.40$ & $12.37 \pm 2.96$ & $<0.001$ & & $<0.001$ & \\
\hline ROM & Pre-treatment & $37.33 \pm 2.57$ & $37.30 \pm 4.38$ & $t=12.99$ & \multirow{2}{*}{1.96} & $t=8.57$ & \multirow{2}{*}{0.80} \\
\hline (Degree) & Post-treatment & $42.67 \pm 2.85$ & $40.90 \pm 4.51$ & $<0.001$ & & $<0.001$ & \\
\hline Muscle & Pre-treatment & $12.24 \pm 2.78$ & $11.73 \pm 2.58$ & $t=10.63$ & \multirow{2}{*}{1.42} & $\mathrm{t}=9.11$ & \multirow{2}{*}{0.95} \\
\hline thickness (mm) & Post-treatment & $8.80 \pm 1.95$ & $9.13 \pm 2.39$ & $<0.001$ & & $<0.001$ & \\
\hline
\end{tabular}




\begin{tabular}{|c|c|c|c|c|c|c|}
\hline Variables & Group & Mean & SD & Std. Error of mean & p-value & Cohen's d \\
\hline \multirow{2}{*}{ VAS } & Laser therapy & -1.83 & 1.01 & 0.18 & \multirow[t]{2}{*}{0.225} & \multirow{2}{*}{0.31} \\
\hline & Dry needling & -2.16 & 1.08 & 0.19 & & \\
\hline \multirow{2}{*}{ ROM } & Laser therapy & 3.6 & 2.29 & 0.41 & \multirow{2}{*}{0.005} & \multirow{2}{*}{0.76} \\
\hline & Dry needling & 5.33 & 2.24 & 0.41 & & \\
\hline \multirow{2}{*}{ Muscle Thickness } & Laser therapy & -2.6 & 1.56 & 0.28 & \multirow{2}{*}{0.55} & \multirow{2}{*}{0.50} \\
\hline & Dry needling & -3.44 & 1.77 & 0.32 & & \\
\hline \multirow{2}{*}{ PPT } & Laser therapy & 2.78 & 1.4 & 0.25 & \multirow{2}{*}{0.009} & \multirow{2}{*}{0.70} \\
\hline & Dry needling & 4.27 & 2.62 & 0.47 & & \\
\hline
\end{tabular}

SD: standard deviation, VAS: visual analog scale, ROM: range of motion, PPT: pressure pain threshold

statistically significant improvement in the DN group in terms of PPT $(\mathrm{P}=0.009)$ and $\mathrm{ROM}(\mathrm{P}=0.005)$ compared to the LLLT group. However, differences in the other two outcome measures were statistically significant. Intergroup effects sizes were found to be extensive $(d>0.5)$ in all outcomes (Table 4$)$.

\section{Discussion}

According to the findings, the application of LLLT and DN increased the active cervical lateral flexion and PPT and decreased VAS and UT thickness. These results indicated the high effectiveness of these interventions in the patients. It must be noted that the effect size of these interventions was above one. Based on the results, it can be said that DN was more effective, compared to LLLT, regarding PPT and ROM. However, the differences between the LLLT group and the DN group were not significant in terms of the other dependent variables, namely VAS and muscle thickness. The effect size variables confirmed the results $(\mathrm{d}>0.5)$.

Improvement in outcomes was observed in both groups, which can be attributed to the therapeutic benefits of the interventions. To understand the mechanisms behind the improvements, factors for the treatment of MTrPs, including an increase in the length of sarcomeres and blood supply to the MTrP, should be well considered (3).

By the application of LLLT, ROM increases due to the relaxation of tight actin-myosin bonds and improvement of microcirculation which results in the interruption of the vicious cycle of pain (18). Consequently, improvement in sarcomeres length and circulation can lead to the treatment of MTrPs. Such effects of LLLT as a therapeutic intervention should be viewed with regard to the evidence of its effectiveness.

Results of some of the previous research are in line with those of this study in terms of the efficacy of LLLT on the decrease of symptoms of MTrPs. Shahimoridi et al. (2020) compared the effects of LLLT and polarized low-level laser therapy (PLLT) on the treatment of MTrPs in the trapezius muscle. They found that both techniques effectively treat MTrPs and reduce pain, limitation of neck movement, and PPT. However, the effect of the LLLT was more significant in comparison to the PLLLT (52). Waseem et al. (2020) in their study found that the combination of conventional physical therapy and LLLT was more effective than conventional physical therapy alone on PPT and CROM in patients with a trigger point in their UT muscle (53).

Furthermore, Rezaei et al. (2019) evaluated the effect of the combination of laser therapy and ischemic compression of an active myofascial trigger point in the UT muscle. According to their results, the laser therapy combined with ischemic compression increased the PPT and cervical lateral flexion in the patients (54). Similarly, Chang et al. (2020) investigated the effect of LLLT applied to myofascial trigger points and classical acupoints for patients with cervical myofascial pain syndrome. They found that the LLLT applied to trigger points could significantly reduce myofascial pain and increase CROM in these patients (55).

However, in some clinical trials like the one carried out by Dundar et al. (2007), no significant differences were found between the results of patients who received LLLT on neck MTrPs and those who were placebo recipients (29). This controversy could be due to the versatile treatment parameters related to laser therapy (i.e., wavelength, power output, energy intensity, and duration) which lead to various results $(15,56)$.

It can be claimed that the consistency of $\mathrm{DN}$ decreases local muscle contraction, pain, and local palpation tenderness and lengthens the involved muscle. A decrease of the local muscle contraction by the depolarization of the involved muscle fibers can elicit an Ltr (57) which may be associated with an increase in the ROM of the active region (58). Any improvement in ROM may also be due to the analgesic effect of the DN or a combination of the two known effects (59). Consequently, this mechanism can improve VAS, PPT, ROM, and UT thickness (due to decreased UT spasm).

It should be mentioned that the efficacy of DN on MTrPs is a controversial issue. Ziaeifar et al. (2019) investigated the long-term clinical effect of DN on individuals with myofascial trigger points in the UT muscle. They found that DN into the myofascial trigger point of the UT muscle causes an improvement in pain intensity and disability within three months (60). Tabatabaiee et al. (2018) also compared the effects of pressure release, 
phonophoresis, and DN on LMTrPs of the UT muscle. Based on their findings, pain reduction increased ROM, and the PPT was observed in the three groups; however, DN and phonophoresis were more effective than pressure release (61).

Findings of some previous research were consistent with those of this study and indicated positive effects of DN on MTrPs, such as the study performed by Rezaeian et al. (2020), Elzohiery et al. (2020), Abbaszadeh-Amirdehi (2016), and Gerber (2015) (62-65). However, in a meta-analysis of the data carried out by Rodrigues et al. (2016), DN was found to be even less effective on pain relief than placebo (66). Besides, Charles et al. (2019) in a systematic review compared the effects of manual therapy techniques, dry cupping, and dry needling on the reduction of myofascial pain and myofascial trigger points. They confirmed the results of the study carried out by Rodrigues (67). Results of these two studies could have been affected by their limitations, such as small sample sizes, unclear methodologies, poor blinding research methods, and lack of control groups.

According to the review of the related literature on the treatment of trigger points, it can be said that monotherapy may be insufficient for the achievement of a desirable treatment in MPS patients (68). Due to the multiplicity of factors that cause MPS, it can be said that a multifaceted approach to treatment is desirable $(13,69)$. There is growing evidence that DN and LLLT, and stretching exercises are useful alternatives for the management of $\operatorname{MPS}(2,66)$. Hence, stretching exercises were performed daily by the subjects of this study to provide more comprehensive treatment. It must be noted that no studies have compared the efficacy of DN and LLLT on UT LTrPs by a novel application of ultrasound to visualize the UT thickness to prove the efficacy of the interventions. Therefore, this can be considered as the strength of the present study.

In the current study, DN led to a greater increment in the ROM and PPT of the subjects, compared to the LLLT group. There is literature that supports the influence of the LLLT on the management of MTrP; however, we were not able to explain why LLLT could not elicit an outcome similar to DN. This is due to the skepticism about the etiology of trigger point formation in a skeletal muscle and its mechanism of production of somatic symptoms. Moreover, there gaps in knowledge about the mechanism of action, effectiveness, and optimal dosage of LLLT (56), and the mechanism of pain reduction of DN. Advancement of knowledge about these mechanisms will make way for future studies on the potentially effective and efficient treatments of individuals with LTrPs of UT.

\subsection{Study limitations}

It should be noted that the present study had some limitations; a significant limitation was the lack of placebo treatment either in DN or in the LLLT group to rule out the placebo effect. Another limitation of the study was that we did not investigate any function or disability measurements, self-reports of pain, fatigue, mood, disability, function, and health status to clarify if the participants felt clinically better. Hence, it is advisable to carry out randomized, placebo-controlled, blinded trials using a questionnaire to collect data regarding the above-mentioned conditions and beneficial documents of the features of LLLT.

\section{Conclusion}

In this study, it was found that both DN and LLLT were effective treatments for LTrPs of UT. However, the DN group underwent a greater improvement regarding the increase of $\mathrm{PPT}$ and ROM during the treatment sessions. Therefore, it can be said that despite the fact that ROM and PPT increased significantly in both treatment groups, the DN treatment method was more effective.

\section{References}

1. Simons DG, Travell J, Simons LS. Travell \& Simons's myofascial pain and dysfunction: the trigger point manual. $2^{\text {nd }}$ ed. Baltimore: Williams \& Wilkins; 1999. P. 184.

2. Hakgüder A, Birtane M, Gürcan S, Kokino S, Turan FN. Efficacy of low level laser therapy in myofascial pain syndrome: an algometric and thermographic evaluation. Lasers Surg Med. 2003;33(5):339-43. doi: 10.1002/lsm.10241. [PubMed: 14677161].

3. Simons DG. New aspects of myofascial trigger points: etiological and clinical. J Musculoskelet Pain. 2004;12(3):15-21. doi: 10.1300/J094v12n03_03.

4. Abbaszadeh-Amirdehi M, Ansari NN, Naghdi S, Olyaei G, Nourbakhsh MR. The neurophysiological effects of dry needling in patients with upper trapezius myofascial trigger points: study protocol of a controlled clinical trial. BMJ Open. 2013;3(5):e002825. doi: 10.1136/bmjopen-2013-002825. [PubMed: 23793673].

5. Grieve R, Barnett S, Coghill N, Cramp F. The prevalence of latent myofascial trigger points and diagnostic criteria of the triceps surae and upper trapezius: a cross sectional study. Physiotherapy. 2013;99(4):278-84. doi: 10.1016/j.physio.2013.04.002. [PubMed: 23830716].

6. Kalichman L, Vulfsons S. Dry needling in the management of musculoskeletal pain. J Am Board Fam Med. 2010;23(5):640-6. doi: 10.3122/jabfm.2010.05.090296. [PubMed: 20823359].

7. Yeganeh Lari A, Okhovatian F, Naimi SS, Baghban AA. The effect of the combination of dry needling and MET on latent trigger point upper trapezius in females. Man Ther. 2016;21:204-9. doi: 10.1016/j.math.2015.08.004. [PubMed: 26304789].

8. Kietrys DM, Palombaro KM, Azzaretto E, Hubler R, Schaller B, Schlussel JM, et al. Effectiveness of dry needling for upperquarter myofascial pain: a systematic review and metaanalysis. J Orthop Sports Phys Ther. 2013;43(9):620-34. doi: 10.2519/jospt.2013.4668. [PubMed: 23756457].

9. Venere K, Ridgeway K. Trigger point dry needling: the data do not support broad applicability or robust effect. J Man Manip Ther. 2016;24(1):2-4. doi: 10.1080/10669817.2015.1106820. [PubMed: 27252575].

10. Dommerholt J. Dry needling in orthopedic physical therapy practice. Orthop Phys Ther Pract. 2004;16(3):15-20. 
11. Baldry PE, Yunus MB, Inanici F. Myofascial pain and fibromyalgia syndromes. Edinburgh: Churchill Livingstone; 2001.

12. Furlan AD, van Tulder M, Cherkin D, Tsukayama H, Lao L, Koes $B$, et al. Acupuncture and dry-needling for low back pain: an updated systematic review within the framework of the cochrane collaboration. Spine. 2005;30(8):944-63. doi: 10.1097/01.brs.0000158941.21571.01. [PubMed: 15834340].

13. Unverzagt C, Berglund K, Thomas JJ. Dry needling for myofascial trigger point: a clinical commentary. Int J Phys Ther. 2015;10(3):402-18. [PubMed: 26075156].

14. Gross AR, Dziengo S, Boers O, Goldsmith CH, Graham N, Lilge L, et al. Low level laser therapy (LLLT) for neck pain: a systematic review and meta-regression. Open Orthop J. 2013; 7:396-419. doi: 10.2174/1874325001307010396. [PubMed: 24155802].

15. Chow RT, Johnson MI, Lopes-Martins RA, Bjordal JM. Efficacy of low-level laser therapy in the management of neck pain: a systematic review and meta-analysis of randomised placebo or active-treatment controlled trials. Lancet. 2009;374(9705): 1897-908. doi: 10.1016/S0140-6736(09)61522-1. [PubMed: 19913903].

16. Cotler HB, Chow RT, Hamblin MR, Carroll J. The use of low level laser therapy (LLLT) for musculoskeletal pain. MOJ Orthop Rheumatol. 2015;2(5):00068. doi: 10.15406/mojor.2015.02. 00068. [PubMed: 26858986].

17. Bjordal J, Couppe C, Chow R, Tuner J, Ljunggren EA. A systematic review of low level laser therapy with locationspecific doses for pain from chronic joint disorders. Aust $J$ Physiother. 2003;49(2):107-16. doi: 10.1016/s00049514(14)60127-6. [PubMed: 2775206].

18. Simunovic Z. Low level laser therapy with trigger points technique: a clinical study on 243 patients. J Clin Laser Med Surg. 1996;14(4):163-7. doi: 10.1089/clm.1996.14.163. [PubMed: 9456632].

19. Chow RT, David MA, Armati PJ. 830 nm laser irradiation induces varicosity formation, reduces mitochondrial membrane potential and blocks fast axonal flow in small and medium diameter rat dorsal root ganglion neurons: implications for the analgesic effects of 830 nm laser. J Peripher Nerv Syst. 2007;12(1):28-39. doi: 10.1111/j.1529-8027.2007.00114.x. [PubMed: 17374099].

20. Tekin L, Akarsu S, Durmuş O, Cakar E, Dinçer U, Kıralp MZ. The effect of dry needling in the treatment of myofascial pain syndrome: a randomized double-blinded placebo-controlled trial. Clin Rheumatol. 2013;32(3):309-15. doi: 10.1007/s10067-0122112-3. [PubMed: 23138883]

21. Ziaeifar M, Arab AM, Karimi N, Nourbakhsh MR. The effect of dry needling on pain, pressure pain threshold and disability in patients with a myofascial trigger point in the upper trapezius muscle. J Bodyw Mov Ther. 2014;18(2):298-305. doi: 10.1016/j.jbmt.2013.11.004. [PubMed: 24725800].

22. Cerezo-Téllez E, Lacomba MT, Fuentes-Gallardo I, Mayoral Del Moral O, Rodrigo-Medina B, Gutiérrez Ortega C. Dry needling of the trapezius muscle in office workers with neck pain: a randomized clinical trial. J Man Manip Ther. 2016;24(4): 223-32. doi: 10.1179/2042618615Y.0000000004. [PubMed: 27582622].

23. 23- Liu L, Huang QM, Liu QG, Ye G, Bo CZ, Chen MJ, et al. Effectiveness of dry needling for myofascial trigger points associated with neck and shoulder pain: a systematic review and meta-analysis. Arch Phys Med Rehabil. 2015;96(5):944-55. doi: 10.1016/j.apmr.2014.12.015. [PubMed: 25576642].

24. Gur A, Sarac AJ, Cevik R, Altindag O, Sarac S. Efficacy of $904 \mathrm{~nm}$ gallium arsenide low level laser therapy in the management of chronic myofascial pain in the neck: a double-blind and randomize-controlled trial. Lasers Surg Med. 2004;35(3):22935. doi: 10.1002/lsm.20082. [PubMed: 15389743].

25. Yamany AA, Salim SE. Efficacy of low level laser therapy for treatment myofascial trigger points of shoulder pain. World Appl Sci J. 2011;12(6):758-64.

26. Ilbuldu E, Cakmak A, Disci R, Aydin R Comparison of laser, dry needling, and placebo laser treatments in myofascial pain syndrome. Photomed Laser Surg. 2004;22(4):306-11. doi: 10.1089/pho.2004.22.306. [PubMed: 15345173].
27. Cummings TM, White AR. Needling therapies in the management of myofascial trigger point pain: a systematic review. Arch Phys Med Rehabil. 2001;82(7):986-92. doi: 10.1053/apmr.2001.24023. [PubMed: 11441390].

28. Tough EA, White AR, Cummings TM, Richards SH, Campbell JL. Acupuncture and dry needling in the management of myofascial trigger point pain: a systematic review and metaanalysis of randomised controlled trials. Eur J Pain. 2009;13(1):3-10. doi: 10.1016/j.ejpain.2008.02.006. [PubMed: 18395479].

29. Dundar U, Evcik D, Samli F, Pusak H, Kavuncu V. The effect of gallium arsenide aluminum laser therapy in the management of cervical myofascial pain syndrome: a double blind, placebocontrolled study. Clin Rheumatol. 2007;26(6):930-4. doi: 10.1007/s10067-006-0438-4. [PubMed: 17021664].

30. Altan L, Bingöl U, Aykaç M, Yurtkuran M. Investigation of the effect of GaAs laser therapy on cervical myofascial pain syndrome. Rheumatol Int. 2005;25(1):23-7. doi: 10.1007/ s00296-003-0396-y. [PubMed: 14673617].

31. Simons DG, Travell J, Simons LS. Travell \& Simons' myofascial pain and dysfunction. Upper half of body Baltimore. Philadelphia: Lippincott Williams \& Wilkins; 1999.

32. Rezasoltani A. Individual cervical muscle function in biomechanical studies: a review of literature. J Phys Ther Sci. 2001;13(2):139-43. doi: 10.1589/jpts.13.139.

33. Adigozali H, Shadmehr A, Ebrahimi E, Rezasoltani A, Naderi F. Ultrasonography for the assessment of the upper trapezius properties in healthy females: a reliability study. Muscles Ligaments Tendons J. 2016;6(1):167-72. doi: 10.11138/mltj/ 2016.6.1.167. [PubMed: 27331047].

34. Fernández-de-las-Peñas C, Alonso-Blanco C, Miangolarra JC Myofascial trigger points in subjects presenting with mechanical neck pain: a blinded, controlled study. Man Ther. 2007;12(1):29 33. doi: 10.1016/j.math.2006.02.002. [PubMed: 21882489].

35. Gemmell $H$, Miller $P$, Nordstrom $H$. Immediate effect of ischaemic compression and trigger point pressure release on neck pain and upper trapezius trigger points: a randomised controlled trial. Clin Chiropractic. 2008;11(1):30-6. doi: 10.1016/j.clch.2007.09.001.

36. Okhovatian F, Mehdikhani R, Sadat Naimi S. RETRACTED: Comparison between the immediate effect of manual pressure release and strain/counterstrain techniques on latent trigger point of upper trapezius muscle. Clin Chiropractic. 2012;15(2):55-61. doi: 10.1016/j.clch.2012.04.003.

37. Sciotti VM, Mittak VL, DiMarco L, Ford LM, Plezbert J, Santipadri E, et al. Clinical precision of myofascial trigger point location in the trapezius muscle. Pain. 2001;93(3):259-66. doi: 10.1016/S0304-3959(01)00325-6. [PubMed: 11514085].

38. Cotchett MP, Landorf KB, Munteanu SE, Raspovic A. Effectiveness of trigger point dry needling for plantar heel pain: study protocol for a randomised controlled trial. $J$ Foot Ankle Res. 2011;4:5. doi: 10.1186/1757-1146-4-5. [PubMed: 21255460].

39. Taheri P, Vahdatpour B, Andalib S. Comparative study of shock wave therapy and laser therapy effect in elimination of symptoms among patients with myofascial pain syndrome in upper trapezius. Adv Biomed Res. 2016;5:138. doi: 10.4103/2277-9175.187398. [PubMed: 27656607].

40. Cagnie B, Barbe T, De Ridder E, Van Oosterwijck J, Cools A Danneels $\mathrm{L}$. The influence of dry needling of the trapezius muscle on muscle blood flow and oxygenation. I Manipulative Physiol Ther. 2012;35(9):685-9. doi: 10.1016/j.jmpt.2012.10.005. [PubMed: 23206963].

41. Sandberg M, Larsson B, Lindberg LG, Gerdle B. Different patterns of blood flow response in the trapezius muscle following needle stimulation (acupuncture) between healthy subjects and patients with fibromyalgia and work-related trapezius myalgia. Eur J Pain. 2005;9(5):497-510. doi: 10.1016/j.ejpain.2004.11.002. [PubMed: 16139178].

42. Sola AE. Myofascial trigger point therapy. Resid Staff Physician. 1981;27:38-45.

43. Hong CZ. Lidocaine injection versus dry needling to myofascial trigger points: the importance of the local twitch response. Am J Phys Med Rehabil. 1994;73(4):256-63. doi: 10.1097/ 
00002060-199407000-00006. [PubMed: 8043247].

44. Sadria G, Hosseini M, Rezasoltani A, Akbarzadeh Bagheban A, Davari A, Seifolahi A. A comparison of the effect of the active release and muscle energy techniques on the latent trigger points of the upper trapezius. I Bodyw Mov Ther. 2017;21(4):920-5. doi: 10.1016/j.jbmt.2016.10.005. [PubMed: 29037649].

45. Youdas JW, Carey JR, Garrett TR. Reliability of measurements of cervical spine range of motion-comparison of three METhods. Phys Ther. 1991;71(2):98-104. doi: 10.1093/ptj/71.2.98. [PubMed: 1989013].

46. Unalan H, Majlesi J, Aydin FY, Palamar D. Comparison of highpower pain threshold ultrasound therapy with local injection in the treatment of active myofascial trigger points of the upper trapezius muscle. Arch Phys Med Rehabil. 2011;92(4): 657-62. doi: 10.1016/j.apmr.2010.11.030. [PubMed: 21440713].

47. Rowley NC. The relative effectiveness of a single dry needle insertion compared to multiple fanning dry needle insertions in the treatment of myofasciitis in the cervical and upper thoracic spine. [Doctoral Dissertation]. Durban, South Africa: Durban University of Technology; 2001.

48. Hidalgo-Lozano A, Fernández-de-las-Peñas C, Alonso-Blanco C, Ge HY, Arendt-Nielsen L, Arroyo-Morales M. Muscle trigger points and pressure pain hyperalgesia in the shoulder muscles in patients with unilateral shoulder impingement: a blinded, controlled study. Exp Brain Res. 2010;202(4):915-25. doi: 10.1007/s00221-010-2196-4. [PubMed: 20186400].

49. Reeves JL, Jaeger B, Graff-Radford SB. Reliability of the pressure algometer as a measure of myofascial trigger point sensitivity. Pain. 1986;24(3):313-21. doi: 10.1016/03043959(86)90117-X. [PubMed: 3960573].

50. Fischer AA. Pressure algometry over normal muscles. Standard values, validity andreproducibility of pressure threshold. Pain. 1987;30(1):115-26. doi: 10.1016/0304-3959(87)90089-3. [PubMed: 3614975].

51. Seifolahi A, Naimi SS, Soltani A, Hosseini S, Bagheban AA, Sadria G. Reliability of upper trapezius muscle thickness measurement using B-mode ultrasound images in patient with latent trigger point. J Rehabil Med. 2015;4(1):17-25.

52. Shahimoridi D, Shafiei SA, Yousefian B. The effectiveness of the polarized low-level laser in the treatment of patients with myofascial trigger points in the trapezius muscles. J Lasers Med Sci. 2020;11(1):14-9. doi: 10.15171/jlms.2020.04. [PubMed: 32099622].

53. Waseem I, Tanveer F, Fatima A. Can addition of low level laser therapy to conventional physical therapy be beneficial for management of pain and cervical range of motion in patients with trigger point of upper trapezius? Anaesth Pain Intensive Care. 2020;24(1):64-8. doi: 10.35975/apic.v24i1.1228.

54. Rezaei S, Shadmehr A, Tajali SB, Moghadam BA, Jalaei S. The effect of laser therapy and ischemic compression on active trigger points in upper trapezius muscle. J Modern Rehabil. 2019;13(4):221-6. doi: 10.32598/JMR.13.4.221.

55. Chang WH, Tu LW, Pei YC, Chen CK, Wang SH, Wong AM. Comparison of the effects between lasers applied to myofascial trigger points and to classical acupoints for patients with cervical myofascial pain syndrome. Biomed J. 2020; In Press. doi: 10.1016/j.bj.2020.05.020.

56. Basford J. Low intensity laser therapy: still not an established clinical tool. Lasers Surg Med. 1995;16(4):331-42. doi: 10.1002/lsm.1900160404. [PubMed: 7651054].

57. Chen JT, Chung KC, Hou CR, Kuan TS, Chen SM, Hong CZ. Inhibitory effect of dry needling on the spontaneous electrical activity recorded from myofascial trigger spots of rabbit skeletal muscle. Am J Phys Med Rehabil. 2001;80(10):729-35. doi: 10.1097/00002060-200110000-00004. [PubMed: 11562554].

58. Lee SH, Chen CC, Lee CS, Lin TC, Chan RC. Effects of needle electrical intramuscular stimulation on shoulder and cervical myofascial pain syndrome and microcirculation. J Chin Med Assoc. 2008;71(4):200-6. doi: 10.1016/S1726-4901(08)701047. [PubMed: 18436503].

59. Atchabahian A, Schwartz G, Hall CB, Lajam CM, Andreae MH. Regional analgesia for improvement of long-term functional outcome after elective large joint replacement. Cochrane Database Syst Rev. 2015;2015(8):CD010278. doi: 10.1002/14651858.CD010278.pub2. [PubMed: 26269416].

60. Ziaeifar M, Arab AM, Mosallanezhad Z, Nourbakhsh MR. Dry needling versus trigger point compression of the upper trapezius: a randomized clinical trial with two-week and threemonth follow-up. J Man Manip Ther. 2019;27(3):152-61. doi: 10.1080/10669817.2018.1530421. [PubMed: 30935341].

61. Tabatabaiee A, Ebrahimi-Takamjani I, Ahmadi A, Sarrafzadeh J, Emrani A. Comparison of pressure release, phonophoresis and dry needling in treatment of latent myofascial trigger point of upper trapezius muscle. J Back Musculoskelet Rehabil. 2019; 32(4):587-94. doi: 10.3233/BMR-181302. [PubMed: 30584120].

62. Rezaeian T, Mosallanezhad Z, Nourbakhsh MR, Norouzi M, Sajedi F. Effects of dry needling technique into trigger points of the sternocleidomastoid muscle in migraine headache: a randomized controlled trial. Am J Phys Med Rehabil. 2020;99(12): 1129-37. doi: 10.1097/PHM.0000000000001504. [PubMed: 32544109].

63. Ali H, Elzohiery A, Arafa M, Elkadery N. Dry needling versus ultrasonic in treating cervical myofascial pain syndrome. $Q J M$. 2020;113(Suppl 1):hcaa064-5. doi: 10.1093/qjmed/hcaa064.005.

64. Abbaszadeh-Amirdehi M, Ansari NN, Naghdi S, Olyaei G, Nourbakhsh MR. Neurophysiological and clinical effects of dry needling in patients with upper trapezius myofascial trigger points. J Bodyw Mov Ther. 2017;21(1):48-52. doi: 10.1016/j.jbmt.2016.04.014. [PubMed: 28167189].

65. Gerber LH, Shah J, Rosenberger W, Armstrong K, Turo D, Otto $\mathrm{P}$, et al. Dry needling alters trigger points in the upper trapezius muscle and reduces pain in subjects with chronic myofascial pain. PM R. 2015;7(7):711-8. doi: 10.1016/j. pmrj.2015.01.020. [PubMed: 25661462].

66. Rodríguez-Mansilla J, González-Sánchez B, De Toro García Á, Valera-Donoso E, Garrido-Ardila EM, Jiménez-Palomares M, et al. Effectiveness of dry needling on reducing pain intensity in patients with myofascial pain syndrome: a Meta-analysis. $J$ Tradit Chin Med. 2016;36(1):1-13. doi: 10.1016/s02546272(16)30001-2. [PubMed: 26946612].

67. Charles D, Hudgins T, MacNaughton J, Newman E, Tan J, Wigger M. A systematic review of manual therapy techniques, dry cupping and dry needling in the reduction of myofascial pain and myofascial trigger points. J Bodyw Mov Ther. 2019; 23(3):539-46. doi: 10.1016/j.jbmt.2019.04.001. [PubMed: 31563367].

68. Koca İ, Boyaci A. A new insight into the management of myofascial pain syndrome. Gaziantep Med J. 2014;20(2):107-2. doi: $10.5455 /$ GMJ-30-149824.

69. Fleckenstein J, Zaps D, Rüger LJ, Lehmeyer L, Freiberg F, Lang PM, et al. Discrepancy between prevalence and perceived effectiveness of treatment methods in myofascial pain syndrome: results of a cross-sectional, nationwide survey. $B M C$ Musculoskelet Disord. 2010;11(1):32. doi: 10.1186/14712474-11-32. [PubMed: 20149248]. 